\title{
ACUTE CONFUSIONAL STATE IN ELDERLY- AETIOLOGY AND CLINICAL FEATURES
}

\author{
Samarendra Nath Das ${ }^{1}$, Rina Mohanty22, Nirmal Chandra Sahu³, Bharani Bellam4, Bibhuti Bhusan Mohanta ${ }^{5}$, \\ Sarada Priyadarsini Suna ${ }^{6}$, Laxmidhar Sendha $^{7}$, Pravat Kumar Thatoi ${ }^{8}$
}

${ }^{1}$ Associate Professor, Department of Medicine, SCB Medical College, Cuttack. ${ }^{2}$ Associate Professor, Department of Medicine, SCB Medical College, Cuttack. ${ }^{3}$ Assistant Professor, Department of Medicine, SCB Medical College, Cuttack. ${ }^{4}$ Postgraduate Student, Department of Medicine, SCB Medical College, Cuttack. ${ }^{5}$ Postgraduate Student, Department of Medicine, SCB Medical College, Cuttack. ${ }^{6}$ Postgraduate Student, Department of Medicine, SCB Medical College, Cuttack. ${ }^{7}$ Assistant Surgeon, Chanakya Hospital, Cuttack.

${ }^{8}$ Assistant Professor, Department of Medicine, SCB Medical College, Cuttack.

\begin{tabular}{l}
\hline ABSTRACT \\
Acute confusional state is a common manifestation in elderly persons. Because of its multifactorial aetiology, a wide variety of \\
diseases present as acute confusional state in elderly.
\end{tabular}

\section{MATERIALS AND METHODS}

A descriptive study was conducted in Department of Medicine of SCB Medical College, Cuttack and consecutively 100 adult patients with acute confusional state were included in the study. These patients were studied for the aetiology, clinical features and outcome. Relevant investigations were done in each patient and the data was tabulated.

\section{RESULTS}

Among 100 patients of acute confusional state, 58 (58\%) were male and 42 (42\%) were female patients. Most common aetiology was stroke $(31 \%)$ followed by hyponatraemia (16\%) with the predisposing factors being diabetes mellitus (37\%) and hypertension $(32 \%)$ in order. Most common symptom was vomiting (36\%) followed by fever $(28 \%)$.

\section{CONCLUSION}

Acute confusional state gives physician an alert preceding the illness or events. Early diagnosis and proper management will reduce mortality in elderly.

\section{KEYWORDS}

Confusional State, Stroke, Hyponatraemia.

HOW TO CITE THIS ARTICLE: Das SN, Mohanty R, Sahu NC et al. Acute confusional state in elderly- aetiology and clinical features. J. Evolution Med. Dent. Sci. 2017;6(92):6570-6573, DOI: 10.14260/jemds/2017/1424

\section{BACKGROUND}

Acute confusional state or delirium is a clinical constellation of neurological signs commonly encountered in elderly, i.e. age more than 60 years and is of multifactorial in origin. ${ }^{1} \mathrm{~A}$ study by Grover et al over 6 years among 3092 elderly patients admitted to different wards showed acute confusional state, they form the largest category in elderly patients. $^{2}$ There are many studies which indicate the cause of acute confusional state in geriatric population is multifactorial. A number of potential risk factors have been identified as risk factors for acute confusional state. The search for potential causes for delirium is complicated by frequently atypical disease manifestations in elderly patients in addition to practical difficulties of documenting histories from confused patients. Virtually, all studies found that age is an independent risk factor for acute confusional state. ${ }^{3}$

'Financial or Other Competing Interest': None.

Submission 21-10-2017, Peer Review 17-11-2017,

Acceptance 23-11-2017, Published 04-12-2017.

Corresponding Author:

Dr. Samarendra Nath Das,

Mahatab Road, Cuttack-753012,

Odisha, India.

E-mail: drsamarendranathdas@gmail.com

DOI: $10.14260 /$ jemds $/ 2017 / 1424$

(c) (i) $(9)$
Delirium may be the only sign of a serious or lifethreatening medical condition and is a common manifestation of acute illness in older population. Ageing brings a change in brain and pre-existing cognitive deficits or strokes render nervous system more sensitive to toxic or metabolic insults such as medication side effects, electrolyte imbalances, endocrine disorders, hepatic or renal failure and infections among many other conditions. ${ }^{4}$ Delirium is associated with increased mortality and morbidity. Patients suffering from delirium have initial mortality rate of $26 \%$ to $75 \%$ in three years after an episode of delirium. ${ }^{5}$ The best available evidence suggests that prevention of delirium is more effective than its treatment. ${ }^{6}$ However, clinicians must distinguish acute disorder of delirium from chronic disorder of dementia, which is also prevalent in elderly population. The definition of delirium must emphasise an acute behavioural change with fluctuating attention regardless of aetiology or presence of baseline cognitive deficits. As the incidence is high, it is logical to do a study about the syndromic approach for aetiology and clinical features of acute confusional state in elderly.

\section{MATERIALS AND METHODS}

This study was a descriptive study. After clearance from Institutional Ethics Committee we included consecutively 100 elderly patients, i.e. persons of age more than 60 years with 
acute confusional state admitted to medical wards or ICUs. Written consent was obtained from relatives of each individual participating in the study.

\section{Inclusion Criteria}

Elderly persons of age more than 60 yrs. and fulfilling DSM-IV Criteria for diagnosing delirium were taken into study.7

DSM-IV Criteria for Delirium²-

a) Disturbance of consciousness (reduced clarity of awareness of environment) with reduced ability to focus, sustain or shift attention.

b) A change in cognition or the development of a perceptual disturbance that is not better accounted by a preexisting, established or evolving dementia.

c) The disturbance develops over a short period of time (usually hours to days) and tends to fluctuate during the course of the day.

d) There is evidence from history, physical examination or laboratory findings that the disturbance is caused by the direct physiological consequence of general medical condition.

\section{Exclusion Criteria}

Persons of known psychiatric illness, dementia and of psychoactive substance abuse.

\section{METHODS}

The selected patients were admitted to Department of Medicine of SCB Medical College, Cuttack. Detailed history was taken including history of psychiatric illness, substance abuse, alcohol intake and fever or head injury. Thorough clinical examination was done in each individual. Investigations like complete blood counts (CBC), peripheral smear comment, malaria parasite (Slide and ICT), plasma sugar, serum urea and creatinine, serum electrolytes, liver function tests (LFTs), prothrombin time (PT), INR, urine analysis and CT scan of brain were done in each individual. These patients were carefully followed or their disease outcome. The observed findings and clinical values were recorded accordingly.

\section{Statistical Analysis}

The observed data was statistically analysed by using IBMcompatible Statistical Package for the Social Sciences (SPSS) version 20.0. The qualitative data were expressed as numbers (\%) and tabulation done.

\section{RESULTS}

\begin{tabular}{|c|c|c|c|c|c|c|}
\hline $\begin{array}{c}\text { Age } \\
\text { Groups }\end{array}$ & $\begin{array}{c}\text { Male } \\
\mathbf{N - 5 8}\end{array}$ & $\mathbf{\%}$ & $\begin{array}{c}\text { Female } \\
\mathbf{N - 4 2}\end{array}$ & $\mathbf{\%}$ & $\begin{array}{c}\text { Total } \\
\mathbf{N = 1 0 0}\end{array}$ & $\mathbf{\%}$ \\
\hline $60-65$ & 8 & 6.6 & 6 & 5 & 14 & 14 \\
\hline $66-70$ & 22 & 37.9 & 12 & 10 & 34 & 34 \\
\hline $71-75$ & 7 & 5.8 & 3 & 2.5 & 10 & 10 \\
\hline $76-80$ & 10 & 8.3 & 13 & 11.2 & 23 & 23 \\
\hline $81-85$ & 6 & 5 & 4 & 3.1 & 10 & 10 \\
\hline $86-90$ & 5 & 4.1 & 3 & 2.5 & 9 & 9 \\
\hline
\end{tabular}

Table 1. Age and Sex Distribution of Patients with Delirium

Out of 100 patients studied $58(58 \%)$ were male and 42 (42\%) were female. In our study, maximum number (34\%) of male and female patients were observed in the age group of 66 - 70 years.

\begin{tabular}{|c|c|c|}
\hline Haemorrhagic stroke & 22 & 22 \\
\hline Hyponatraemia & 16 & 16 \\
\hline Non-haemorrhagic stroke & 9 & 9 \\
\hline Hypoglycaemia & 11 & 11 \\
\hline Hypertensive encephalopathy & 10 & 10 \\
\hline Sepsis & 3 & 3 \\
\hline Uraemic encephalopathy & 6 & 6 \\
\hline Hypercapnia & 4 & 4 \\
\hline Hyperglycaemia & 4 & 4 \\
\hline ICSOL & 6 & 6 \\
\hline Cerebral malaria & 4 & 4 \\
\hline Hypovolaemic shock & 1 & 1 \\
\hline Viral encephalitis & 2 & 2 \\
\hline TB meningitis & 2 & 2 \\
\hline \multicolumn{2}{|c|}{ Table 2. Causes of Delirium } \\
\hline
\end{tabular}

In our study, most common cause of delirium was stroke (both haemorrhagic and non-haemorrhagic, 31\%), out of which haemorrhagic stroke was 22 (22\%) and nonhaemorrhagic stroke was $9(9 \%)$ followed by hyponatraemia $(16 \%)$. We observed stroke was more common than metabolic causes of delirium.

\begin{tabular}{|c|c|c|}
\hline Symptoms & No. of Cases & \% \\
\hline Fever & 28 & 28 \\
\hline Vomiting & 36 & 36 \\
\hline Breathlessness & 10 & 10 \\
\hline Seizures & 8 & 8 \\
\hline Decreased urination & 8 & 8 \\
\hline Headache & 10 & 10 \\
\hline \multicolumn{2}{|c|}{ Table 3. Presenting Features apart from } \\
Delirium in Elderly \\
\hline
\end{tabular}

Out of 100 patients, 36 (36\%) patients presented with vomiting and $28(28 \%)$ presented with fever apart from delirium. Associated co-morbid conditions, e.g. diabetes mellitus was found in 37 patients (37\%) and hypertension was found in 32 patients (32\%).

\begin{tabular}{|c|c|c|}
\hline Causes & No. of Cases (n= 37) & \% \\
\hline Hyponatraemia & 2 & 5.4 \\
\hline Haemorrhagic stroke & 4 & 10.8 \\
\hline Non-haemorrhagic stroke & 7 & 18.9 \\
\hline Hypoglycaemia & 11 & 29.7 \\
\hline Sepsis & 3 & 8.1 \\
\hline Uremic encephalopathy & 5 & 13.5 \\
\hline Hyperglycaemia & 4 & 10.8 \\
\hline Hypovolemic shock & 1 & 2.7 \\
\hline \multicolumn{2}{|c|}{ Table 4. Causes of Delirium in Patients with } \\
Diabetes Mellitus \\
\hline
\end{tabular}

In persons with diabetes mellitus $(n=37)$, we found hypoglycaemia in 11 persons (29.7\%) followed by nonhaemorrhagic stroke in 7 persons $(18.9 \%)$ as the cause of acute confusional state.

\begin{tabular}{|c|c|c|}
\hline Cause & No. of Cases (n= 32) & $\mathbf{\%}$ \\
\hline Hyponatraemia & 3 & 9.3 \\
\hline Haemorrhagic stroke & 10 & 31.2 \\
\hline Non-haemorrhagic stroke & 1 & 3.1 \\
\hline Hypoglycaemia & 5 & 15.6 \\
\hline
\end{tabular}




\begin{tabular}{|c|c|c|}
\hline Hypertensive encephalopathy & 10 & 31.2 \\
\hline Uraemic encephalopathy & 3 & 9.3 \\
\hline \multicolumn{2}{|c|}{ Table 5. Hypertensive with Delirium } \\
\hline
\end{tabular}

In persons with hypertension $(n=32)$, we found haemorrhagic stroke is the commonest cause $(31.2 \%)$ of acute confusional state.

\begin{tabular}{|c|c|c|c|c|c|c|}
\hline $\begin{array}{c}\text { Age } \\
\text { Groups }\end{array}$ & $\begin{array}{c}\text { Male } \\
\mathbf{n = 1 0}\end{array}$ & $\mathbf{\%}$ & $\begin{array}{c}\text { Female } \\
\mathbf{n = 6}\end{array}$ & $\mathbf{\%}$ & $\begin{array}{c}\text { Total } \\
\mathbf{n = 1 6}\end{array}$ & $\mathbf{\%}$ \\
\hline $60-65$ & 2 & 12.5 & 1 & 6.25 & 3 & 18.75 \\
\hline $66-70$ & 3 & 18.75 & 3 & 18.75 & 6 & 37.5 \\
\hline $71-75$ & 2 & 12.5 & - & - & 2 & 12.5 \\
\hline $76-80$ & 2 & 12.5 & 1 & 6.25 & 3 & 18.75 \\
\hline $81-85$ & - & - & 1 & 6.25 & 1 & 6.25 \\
\hline $86-90$ & 1 & 6.25 & - & - & 1 & 6.25 \\
\hline
\end{tabular}

Table 6. Age and Sex Distribution of Patients with Hyponatraemia

\begin{tabular}{|c|c|c|c|c|c|c|}
\hline $\begin{array}{c}\text { Age } \\
\text { Groups }\end{array}$ & $\begin{array}{c}\text { Male } \\
\mathbf{n = 2 0}\end{array}$ & $\mathbf{\%}$ & $\begin{array}{c}\text { Female } \\
\mathbf{n = 1 1}\end{array}$ & $\mathbf{\%}$ & $\begin{array}{c}\text { Total } \\
\mathbf{n = 3 1}\end{array}$ & $\mathbf{\%}$ \\
\hline $60-65$ & 6 & 30 & 2 & 18.1 & 8 & 25.8 \\
\hline $66-70$ & 4 & 20 & 2 & 18.1 & 6 & 19.3 \\
\hline $71-75$ & 3 & 15 & 2 & 18.1 & 5 & 16.1 \\
\hline $76-80$ & 4 & 20 & 3 & 27.2 & 7 & 22.5 \\
\hline $81-85$ & 1 & 5 & 1 & 9 & 2 & 6.4 \\
\hline $86-90$ & 2 & 10 & 1 & 9 & 3 & 9.6 \\
\hline
\end{tabular}

Table 7. Age and Sex Distribution of Patients with Stroke

\begin{tabular}{|c|c|c|c|c|}
\hline $\begin{array}{c}\text { Risk } \\
\text { Factors }\end{array}$ & $\begin{array}{c}\text { Haemorrhage } \\
\mathbf{n = 2 2}\end{array}$ & $\begin{array}{c}\text { Infarction } \\
\mathbf{n = 9}\end{array}$ & $\begin{array}{c}\text { Total } \\
\mathbf{n = 3 1}\end{array}$ & $\mathbf{\%}$ \\
\hline Diabetes mellitus & 4 & 7 & 11 & 35.4 \\
\hline Hypertension & 10 & 1 & 11 & 35.4 \\
\hline Cardiac diseases & 3 & 1 & 4 & 12.9 \\
\hline Dyslipidaemia & 5 & - & 5 & 16.1 \\
\hline
\end{tabular}

Table 8. Risk Factors in Patients of Stroke, $n=31$

In our study, we found diabetes mellitus and hypertension are common risk factors for stroke each having $35.4 \%$. However, for haemorrhagic stroke hypertension and nonhaemorrhagic stroke diabetes mellitus being the commonest cause.

\begin{tabular}{|c|c|c|}
\hline Predisposing Factors & No. of Cases, $n=16$ & $\%$ \\
\hline Diuretic use & 8 & 50 \\
\hline Vomiting & 6 & 37.5 \\
\hline Stroke & 2 & 2.6 \\
\hline
\end{tabular}

In our study, we found diuretic use (50\%) is the commonest cause of hyponatraemia followed by vomiting (37.5\%).

\begin{tabular}{|c|c|c|}
\hline Sr. Sodium (mEq/ L) & $\begin{array}{c}\text { No. of Cases with Seizures } \\
\mathbf{n = 8}\end{array}$ & $\mathbf{\%}$ \\
\hline $130-134$ & - & - \\
\hline $125-129$ & 1 & 12.5 \\
\hline $120-124$ & 1 & 12.5 \\
\hline $110-119$ & 2 & 25 \\
\hline$<110$ & 4 & 50 \\
\hline \multicolumn{2}{|c|}{ Table 10. Co-relation of Serum Sodium Values with } \\
\hline
\end{tabular}

In our study, we found 8 patients with seizures (50\%) in hyponatraemia $(n=16)$ and chance increases when serum sodium is less than $110 \mathrm{mEq} / \mathrm{L}$.

\begin{tabular}{|c|c|}
\hline Causes & No. of Deaths n= 10 \\
\hline Hyponatraemia & 1 \\
\hline Haemorrhagic stroke & 2 \\
\hline Non-haemorrhagic stroke & 1 \\
\hline Hypoglycaemia & - \\
\hline Hypertensive encephalopathy & 1 \\
\hline Septicaemia & 1 \\
\hline Uraemic encephalopathy & - \\
\hline Hypercapnia & - \\
\hline Hyperglycaemia & - \\
\hline ICSOL & 3 \\
\hline Cerebral malaria & - \\
\hline Hypovolaemia & - \\
\hline Table 11. Mortality in Patients with Delirium \\
\hline
\end{tabular}

\section{DISCUSSION}

In our study out of 100 patients, 58 were males and 42 were females, M: F ratio is 1.3: 1 [Table 1]. Our study showed that the incidence of delirium was almost equal in both genders and also the most common age group was 66 - 70 yrs. in both males and females. A study by Khurana et al of 400 patients with delirium of elderly more than 60 yrs. age in 2011 showed M: F ratio of 3: $1 .^{8}$ Aging changes in brain and especially pre-existing cognitive deficits or strokes render the nervous system more sensitive to toxic or metabolic insults in Table 2. Our study showed stroke was the most common cause of delirium (31\%) followed by hyponatraemia (16\%). In our study out of 100 patients, 37 were suffering from diabetes mellitus and amongst them most common cause of the delirium was hypoglycaemia (29\%) followed by nonhaemorrhagic stroke (18.9\%), same as study by Yatin Pal Singh Balhara et al. $^{9}$ In our study, hyponatraemia was the second commonest cause $(16 \%)$ and the affected age group was 66 - 70 yrs. (37.5\%). Male-to-female ratio was 1.6: 1 as compared to study by Nandini Chatterjee et al ${ }^{10}$ in 2012 . Out of 16 patients with hyponatraemia, $50 \%$ had history of diuretic use and $37.5 \%$ had vomiting. In study by Nandini Chatterjee et al,10 most common being the fluid loss due to vomiting or diarrhoea (64\%). $25 \%$ cases of hyponatraemia were having seizures with serum sodium values of $110-119$ $\mathrm{mEq} / \mathrm{L}$ in comparison to $50 \%$ of hyponatraemia patients had seizures when serum sodium values were less than 110 $\mathrm{mEq} / \mathrm{L}$ [Table 10]. In our study, hypertension and diabetes mellitus were common risk factors each sharing $35.4 \%$. In our study, mortality rate in delirium patients was 10\% [Table 11], similar to study by Khurana et al. ${ }^{8}$

\section{CONCLUSION}

Prevalence of acute confusional state or delirium in elderly is common in medical wards, which varies from $14 \%-60 \%$. Multifactorial aetiology came out of this study with most common being stroke followed by hyponatraemia. Diabetes mellitus and hypertension are common underlying risk factors in our study. Diuretic use is one of the common factors for hyponatraemia. However, a large sample size study is to be done to find out nature of the illness. 


\section{REFERENCES}

[1] Mendez MF, Padilla CR. Delirium. Bradley neurology in clinical practice. 2016;2:23-33.

[2] Grover S, Kate N. Delirium research: contribution from India. Developments of Psychiatry in India 2015:46390.

[3] Sandberg O, Gustafson Y, Brannstrom B, et al. Clinical profile of delirium in older patients. J Am Geriatr Soc 1999;47(11):1300-6.

[4] Inouye SK. The dilemma of delirium: clinical and research controversies regarding diagnosis and evaluation of delirium in hospitalized elderly medical patients. Am J Med 1994;97(3):278-88.

[5] Roche V. Southwestern Internal Medicine Conference. Etiology and management of delirium. Am J Med Sci 2003;325(1):23-30.
[6] Rockwood K. The occurrence and duration of symptoms in elderly patients with delirium. J Gerontol 1993;48(4):62-6.

[7] www.WHO.Int/health info/ survey/ageing defolder/index.html\# content.

[8] Khurana V, Gambhir IS, Kishore D. Evaluation of delirium in elderly: a hospital based study. Geriatrics and Gerontology International 2011;11(4):467-73.

[9] Balhara YPS. Diabetes and psychiatry disorders. Indian Journal of Endocrinology and Metabolism 2011;15(4):274-83.

[10] Chatterjee N, Sengupta N, Das C, et al. A descriptive study of hyponatremia in a tertiary care hospital of Eastern India. Indian J Endocr Metab 2012;16(2):28891. 